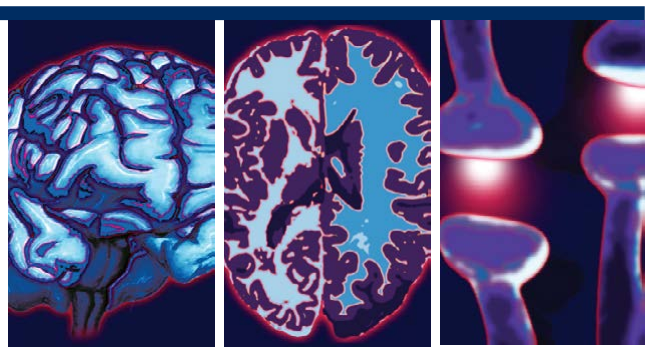

\title{
A Scientometric research on the relationship between psychological factors and oncology based on paper bibliographic coupling analysis
}

\author{
Ying $\mathrm{Wu}^{+, 1}$, Xing Jin ${ }^{2}$, Zhizhong Wang ${ }^{1}$,Yunzhen Xue', Lei Jing ${ }^{1}$,Tao Zhang ${ }^{1}$
}

\begin{abstract}
As a major public health problem in the world, cancer does great harm to human health. With the study on cancer changing from the mode of biology to biopsychosocial, people begin to use psychological method to cure for cancer. So, the relationship between psychological factors and oncology is closely related.

We selected research manuscripts from core collection in Web of Science from 2000 to 2014. We mainly used paper bibliographic coupling analysis by information visualization software $\left(\mathrm{SCi}^{2)}\right.$.

In this study, we can detect that the carcinogenic mechanism of psychological factor, the breast cancer patients' psychological state and psychological situation on life quality of the cancer patients has been always research topics. In recent years, the function of psychological intervention for chronic pain of the cancer patients, psychological assessment scales for the cancer patients, the combined effect of psychological intervention and pharmaceutical drug for the cancer patients and the influence of psychotherapeutic interventions on symptoms of mental disease and disease progression and mortality on cancer patients were added to hot research directions.

This study built mapping knowledge domain of paper bibliographic coupling by the visualization software $\left(\mathrm{Sci}^{2}\right)$, we can reveal the important authors and research direction clearly in different period of time in this field, in order to provide a scientific basis for researchers and policy makers in this field and acquire more valuable information and promote rapid development of this area.
\end{abstract}

\section{Keywords}

Psychology, Oncology, Paper bibliographic coupling, Mapping knowledge domain

\section{Introduction}

As a major public health problem in the world, cancer does great harm to human health. In recent years, studies on cancer have made a series of major breakthroughs and progress, but the morbidity and mortality were rising rapidly. With people gradually realizing the psychological factors' influence on the occurrence, development and outcome of cancer, the study on cancer change from the mode of biology to biopsychosocial. So, people begin to use psychological method to cure for cancer. Psychology and oncology have close relationship, even deriving a new discipline psycho-oncology. Studying on cancer

'School of Humanities and Social Sciences, Shanxi Medical University, Taiyuan, China

${ }^{2}$ Affiliated Tumor Hospital, Shanxi Medical University, Taiyuan, 030013, China

${ }^{\dagger}$ Author for correspondence: Ying Wu, School of Humanities and Social Sciences, Shanxi Medical University, Taiyuan 030001, China. Tel: +8603514135095; Fax: 0351-4135095, email: wuguaiguai9896@126.com 
patients with pressure and their psychological response at all stages of disease process and the function of psychological factors in cancer outcome originated in the 1980s and covered oncology ,sociology, psychology and ethics [1]. After nearly 30 years of development, the complete theoretical system has been formed. Therefore, analyzing its developmental trend, finding important academic literature, academic authors and discussing the research focus and forefront is a valuable study.

\section{Methods}

We selected 13275 manuscripts which consisted all retrieval type to be $\mathrm{TS}=$ (psychological OR psychology) AND TS=(oncology OR cancer OR tumor) from core collection in Web of Science from 2000 to 2014 . The time was divided into three time periods (2000-2004, 2005-2009 and 2010-2014). The date of each bibliographic record contained the title, author names, abstract, key words and reference, et al.

Bibliograhic coupling analysis which the American scholar MM. Kessler come up with firstly in "Bibiographic coupling between scientific papers" in 1963. In the 1980s, Vladntz and Cook published "Biliographic coupling and subject relateness" which has demonstrated the correlation between bibliographic coupling and the subject $[2,3]$. Bibliographic coupling includes paper bibliographic coupling, author bibliographic coupling and Journal bibliographic coupling, et al. In this study, we mainly used papers bibliographic coupling analysis which is that if more than two papers cite the same paper, the relationship of these papers is coupling. The strength of coupling is measured by the number of the references. The more is the number of the co-cited references, the more similar is the direction of study.

In this study, we used the software $\mathrm{Sci}^{2}$ to visual the mapping knowledge domain of the relationship between psychological factors and oncology in which we can detect collaborative relationship vividly by the size of nodes and coupling intensity in clustered papers. $\mathrm{Sci}^{2}$ which built the mapping knowledge and its advantage in visualization was developed by Katy Borner and her team in Indiana University [4].

The flow chart of paper bibliographic coupling analysis was shown in Figure 1.

\section{Results}

In this study, we divided the period of time (20002014) into three stages and built three mapping knowledge domains of paper bibliographic coupling respectively. From constructive analysis of mapping knowledge domains in three periods of time, we can detect the developmental feature and study trend in order to provide reference for development in this field.

\section{- From 2000 to 2004}

There were totally 2569 databases. We firstly drew paper bibliographic coupling map from 2000 to 2004 (Figure 2). In this network, there were totally 47203 nodes among which there were residual 1584 nodes except isolated nodes. There were totally 89665 lines which the maximum weight was 78 and the minimum weight was 1 . The network was reduced to 1582 lines by 'pathfinder' algorithm. In order to analysis the coupling, we selected nodes which the weight is more than 40. In this whole map, the nodes were tight coupling and there were totally four strong coupling papers (Table 1 ).

The first coupling papers were "Group interventions for patients with cancer and HIV disease: Part I : Effects on psychosocial and functional outcomes at different phases of illness" written by Sherman AC in 2004 [5] and "Group interventions for patients with cancer and HIV disease: Part III: Moderating variables and mechanisms of action" also written by Sherman AC in 2004 [6] and the strength of coupling was 78. Their primary domain of research was that the group interventions for individuals facing cancer or HIV disease have drawn considerable attention among researchers and clinicians over the past 20 years. The second coupling papers included two coupled pairs. The first was "Improving the human side of cancer care: Psycho-oncology's contribution" written by Holland JC in 2001 [7] and "History of psycho-oncology: Overcoming attitudinal and conceptual barriers" also written by Holland JC in 2002 [8] and the strength of coupling was 61. The second was "Improving the human side of cancer care: Psycho-oncology's contribution" written by Holland JC in 2001 [7] and "Psychological care of patients: Psycho-oncology's contribution" also written by Holland JC [9] and the strength of coupling was 61. Their primary domain of research was psychological contribution of cancer care. The third coupling papers were "Psychogenesis of cancer: between myths, misuses and reality" written by Reynaert $C$ in 2000 [10] and "Psychogenesis of cancer: towards a psycho-neuro-endocrino-immunolgical way" also written by Reynaert C in 2000 [11] and 
the strength of coupling was 50. Their primary domain of research was psychological factors contributing to the psychogenesis of cancer. The forth coupling papers were "The influence of psychosocial factors on immune system (psychoneuroimmunology) and their role for the incidence and progression of cancer" written by Schussler G in 2001 [12] and "Psychological factors and cancer development Evidence after 30 years of research"written by Garssen B in 2004 [13] and the strength of coupling was 41. Their primary domain of research was the influence of psychosocial factors on the cancer.

\section{- From 2005 to 2009}

There were totally 4247 databases. We firstly drew paper bibliographic coupling map from 2005 to 2009 (Figure 3). In this network, there were totally 74672 nodes among which there was residual 2377 nodes except isolated nodes. There were totally 157008 lines which the maximum weight was 54 and the minimum weight was 1. The network was reduced to 2371 lines by 'pathfinder' algorithm. In order to analyze the coupling, we selected nodes which the weight is more than 40 . In this whole map, the nodes were tight coupling and there were totally five strong coupling papers (Table 2).

The first coupling papers included three coupled pairs. The first was "Inegrative nonpharmacologic behavioral interventions for the management of cancer-related fatigue" written by Mustian KM in 2007 [14] and "Cancer-related fatigue: A systematic and mata-analytic review of nonpharmacological therapies for cancer patients" written by Kangas in 2008 [15] and the strength of coupling was 54. The second was "Psychosocial interventions for reducing fatigue during cancer treatment in adults" written by Goedendorp MM in 2009 [16] and "Cancerrelated fatigue: A systematic and mata-analytic review of non-pharmacological therapies for cancer patients" written by Kangas in 2008 [15] and the strength of coupling was 48. The third was "Cancer-related fatigue: The evidence base for assessment and management" written by Mitchell SA in 2006 [17] and "Cancerrelated fatigue: A systematic and mata-analytic review of non-pharmacological therapies for cancer patients" written by Kangas in 2008 [15] and the strength of coupling was 41 . Their primary domain of research was psychosocial interventions for cancer-related symptom. The second coupling papers were "Quility of life in patients with bladder cancer" written by Gerharz

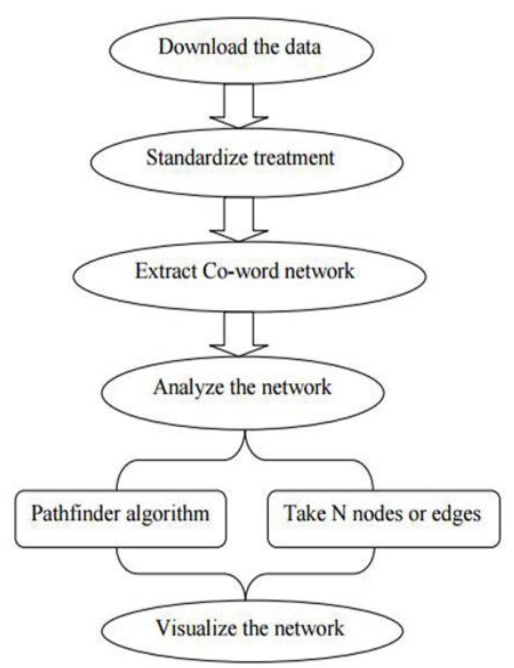

Figure 1: The flow chart of paper bibliographic coupling analysis.

EM in 2005 [18] and "Quality of life after cystectomy and urinary diversion: An evidence based analysis" also written by Gerharz EW in 2005 [19] and the strength of coupling was 48. Their primary domain of research was the influences on common psychosocial factors for quality of life in patients with cancer. The third coupling papers were "Common psychosocial factors underlying breast cancer screening and breast cancer treatment adherence: A conceptual review and synthesis" written by Magai $C$ in 2007 [20] and "Psychosocial influences on suboptimal adjuvant breast cancer treatment adherence among African American women implications for education and intervention" also written by Magai C in 2008 [21] and the strength of coupling was 43 . Their primary domain of research was psychosocial influences on breast cancer treatment adherence among women. The forth coupling papers were "Baseline psychosocial predictors of survival in localized melanoma" written by Lehto US in 2007 [22] and "Baseline psychosocial predictors of survival in localized breast cancer" written by Lehto US in 2006 [23] and the strength of coupling was 41. Their primary domain of research was the impact of psychosocial factors for survival in cancer patient. The fifth coupling papers were "Optimism, social support, and coping strategies as factors contributing to posttraumatic growth: A mata-analysis" written by Prati G in 2009 [24] and "A meta-analytic review of benefit finding and growth" written by Helgeston VS in 2006 [25] and the strength of coupling was 40. Their primary domain of research was the contributing of psychological factors to posttraumatic growth. 


\section{Research Ying Wu}

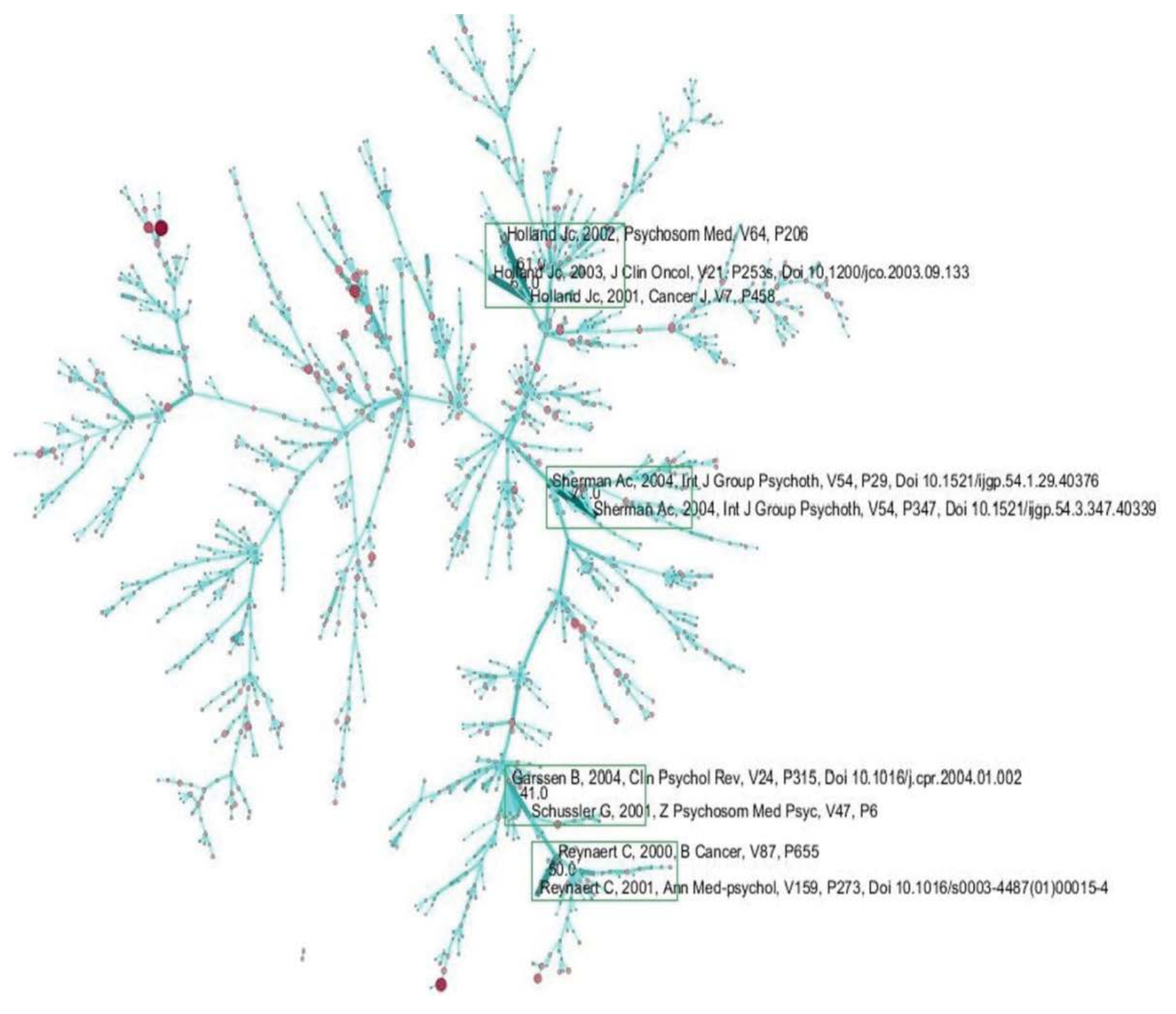

Figure 2: The paper bibliographic coupling map (2000 -2004).

\begin{tabular}{|c|c|c|c|c|}
\hline Ranks & Paper name & Author & Group & $\begin{array}{l}\text { Max of coupling } \\
\text { strength }\end{array}$ \\
\hline 1 & $\begin{array}{l}\text { Group interventions for patients with cancer and HIV disease: Part I : Effects } \\
\text { on psychosocial and functional outcomes at different phases of illness }\end{array}$ & Sherman AC & 1 & 78 \\
\hline 2 & $\begin{array}{l}\text { Group interventions for patients with cancer and HIV disease: Part III: } \\
\text { Moderating variables and mechanisms of action }\end{array}$ & Sherman AC & & \\
\hline 3 & History of psycho-oncology: Overcoming attitudinal and conceptual barriers & Holland JC & 2 & 61 \\
\hline 4 & Improving the human side of cancer care: Psycho-oncology's contribution & Holland JC & & \\
\hline 5 & Psychological care of patients: Psycho-oncology's contribution & Holland JC & & \\
\hline 6 & Psychogenesis of cancer: between myths, misuses and reality & Reynaert C & 3 & 50 \\
\hline 7 & $\begin{array}{l}\text { Psychogenesis of cancer:towards a psycho-neuro-endocrino-immunolgical } \\
\text { way }\end{array}$ & Reynaert C & & \\
\hline 8 & $\begin{array}{l}\text { The influence of psychosocial factors on immune system } \\
\text { (psychoneuroimmunology) and their role for the incidence and progression } \\
\text { of cancer }\end{array}$ & Schussler G & 4 & 41 \\
\hline 9 & $\begin{array}{l}\text { Psychological factors and cancer development Evidence after } 30 \text { years of } \\
\text { research }\end{array}$ & Garssen B & & \\
\hline
\end{tabular}




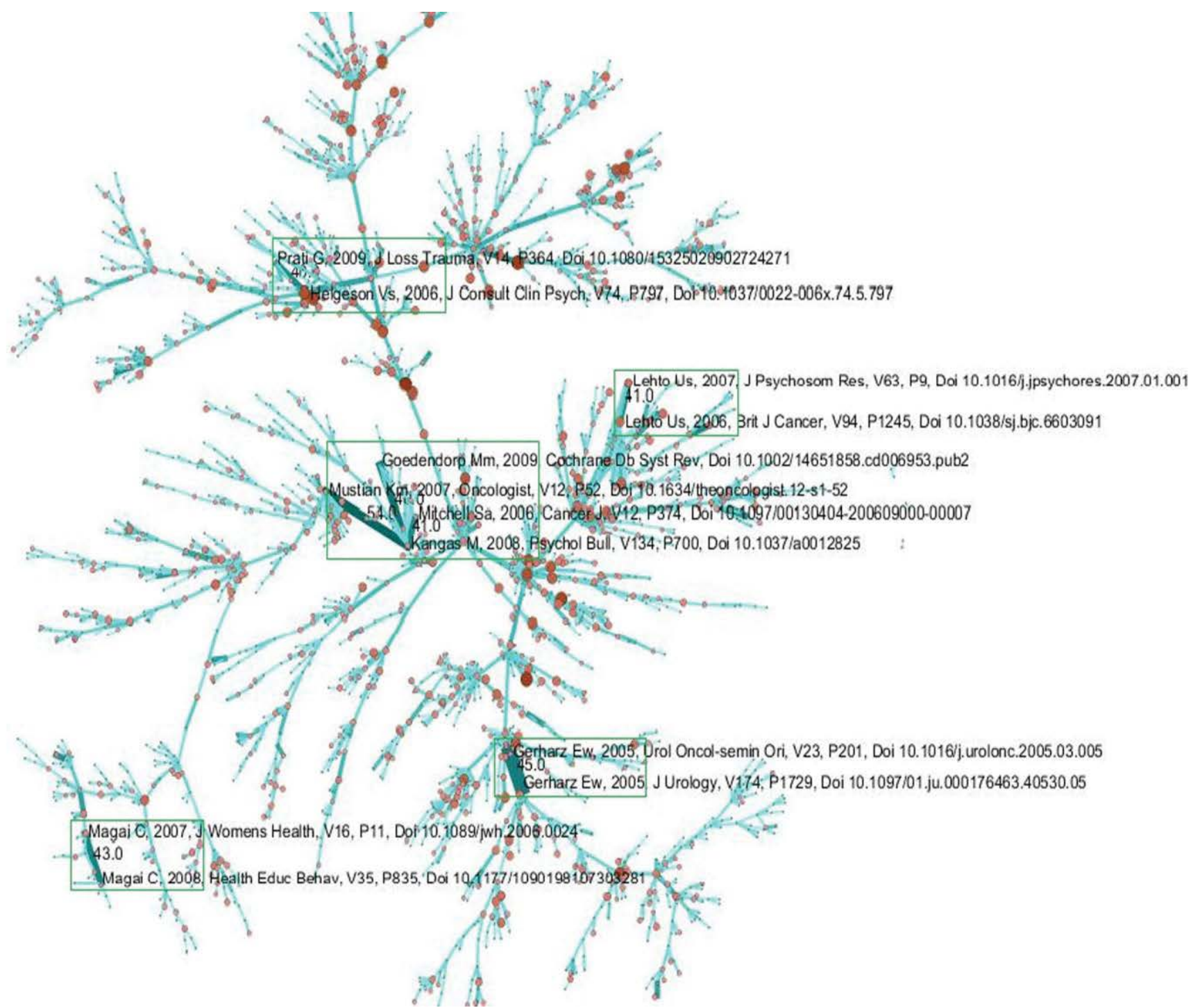

Figure 3: The paper bibliographic coupling map (2005 -2009).

\section{- From 2010 to 2014}

There were totally 6459 databases. We firstly drew paper bibliographic coupling map from 2010 to 2014 (Figure 4). In this network, there were totally 127615 nodes among which there were residual 4228 nodes except isolated nodes. There were totally 434576 lines which the maximum weight was 78 and the minimum weight was 1 . The network was reduced to 4230 lines by 'pathfinder' algorithm. In order to analyze the coupling, we selected nodes which the weight is more than 40 . In this whole map, the nodes were tight coupling and there were totally ten strong coupling papers (Table 3).

The first coupling papers were "Effectiveness of long-term opioid therapy for chronic non-cancer pain” written by Manchikanti L in 2011 [26] and "American society of interventional pain physicians (ASIPP) guidelines for responsible opioid prescribing in chronic non-cancer pain: part 2-guidance" also written by Manchikanti L in 2012 [27] and the strength of coupling were 78 . Their primary domain of research was the effectiveness between psychological factors and chronic pain. The second coupling papers were "Efficacy and safety of pharmacotherapy in cancer-related psychiatric disorders cross the trajectory of cancer care: A review" written by Grassi L in 2014 [28] and "Psychopharmacology in psycho-oncology" written by Caruso $\mathrm{R}$ in 2013 [29] and the strength of coupling was 63. Their primary domain of research was the association between the important tool 


\begin{tabular}{|c|c|c|c|c|}
\hline Ranks & Paper name & Author & Group & $\begin{array}{l}\text { Max of coupling } \\
\text { strength }\end{array}$ \\
\hline 1 & $\begin{array}{l}\text { Inegrative nonpharmacologic behavioral interventions for the management of cancer- } \\
\text { related fatigue }\end{array}$ & Mustian KM & 1 & 54 \\
\hline 2 & $\begin{array}{l}\text { Cancer-related fatigue:A systematic and mata-analytic review of non-pharmacological } \\
\text { therapies for cancer patients }\end{array}$ & Kangas & & \\
\hline 3 & Psychosocial interventions for reducing fatigue during cancer treatment in adults & Goedendorp MM & & \\
\hline 4 & Cancer-related fatigue: The evidence base for assessment and management & Mitchell SA & & \\
\hline 5 & Quility of life in patients with bladder cancer & Gerharz EM & 2 & 48 \\
\hline 6 & Quality of life after cystectomy and urinary diversion: An evidence based analysis & Gerharz EW & & \\
\hline 7 & $\begin{array}{l}\text { Common psychosocial factors underlying breast cancer screening and breast cancer } \\
\text { treatment adherence: A conceptual review and synthesis }\end{array}$ & Magai C & 3 & 43 \\
\hline 8 & $\begin{array}{l}\text { Psychosocial influences on suboptimal adjuvant breast cancer treatment adherence among } \\
\text { African American women implications for education and intervention }\end{array}$ & Magai C & & \\
\hline 9 & Baseline psychosocial predictors of survival in localized melanoma & Lehto US & 4 & 41 \\
\hline 10 & Baseline psychosocial predictors of survival in localized breast cancer & Lehto US & & \\
\hline 11 & $\begin{array}{l}\text { Optimism, social support, and coping strategies as factors contributing to posttraumatic } \\
\text { growth:A mata-analysis }\end{array}$ & Prati G & 5 & 40 \\
\hline 12 & A meta-analytic review of benefit finding and growth & Helgeston VS & & \\
\hline
\end{tabular}

\begin{tabular}{|c|c|c|c|c|}
\hline Ranks & Paper name & Author & Group & $\begin{array}{l}\text { Max of coupling } \\
\text { strength }\end{array}$ \\
\hline 1 & Effectiveness of long-term opioid therapy for chronic non-cancer pain & Manchikanti L & 1 & 78 \\
\hline 2 & $\begin{array}{l}\text { American Society of Interventional Pain Physicians (ASIPP) Guidelines for Responsible } \\
\text { Opioid Prescribing in Chronic Non-Cancer Pain: Part 2-Guidance }\end{array}$ & Manchikanti L & & \\
\hline 3 & $\begin{array}{l}\text { Efficacy and safety of pharmacotherapy in cancer-related psychiatric disorders cross } \\
\text { the trajectory of cancer care: A review }\end{array}$ & Grassi L & 2 & 63 \\
\hline 4 & Psychopharmacology in psycho-oncology & Caruso $\mathrm{R}$ & & \\
\hline 5 & $\begin{array}{l}\text { Long-term and late effects of germ cell testicular cancer treatment and implications for } \\
\text { follow-up }\end{array}$ & Haugnes HS & 3 & 62 \\
\hline 6 & Testicular cancer survivorship: research strategies and recommendations & Travis LB & & \\
\hline 7 & Evidence-based treatment of depression in patients with cancer & Li M & 4 & 61 \\
\hline 8 & $\begin{array}{l}\text { The Canadian network for mood and anxiety treatments (CANMAT) task force } \\
\text { recommendations for the management of patients with mood disorders and select } \\
\text { comorbid medical conditions }\end{array}$ & Ramasubbu R & & \\
\hline 9 & $\begin{array}{l}\text { Biobehavioral factors and cancer progression: physiological pathways and } \\
\text { mechanisms }\end{array}$ & Lutgendort SK & 5 & 49 \\
\hline 10 & $\begin{array}{l}\text { Host factors and cancer progression: biobehavioral signaling pathways and } \\
\text { interventions }\end{array}$ & Lutgendort SK & & \\
\hline 11 & Impact of stress on cancer metastasis & Moreno-Smith M & & \\
\hline 12 & Srcactivation by beta-adrenoreceptors is a key switch for tumor metastasis & Armaiz-Pena GN & & \\
\hline 13 & $\begin{array}{l}\text { Persistent pain in postmastectomy patients: comparison of psychophysical medical, } \\
\text { surgical, and psychosocial characteristics between patients with and without pain }\end{array}$ & Schreiber & 6 & 49 \\
\hline 14 & $\begin{array}{l}\text { Persistent postmastectomy pain breast cancer survivors: analysis of clinical, } \\
\text { demographic, and psychosocial factors }\end{array}$ & Belfer $\mathrm{L}$ & & \\
\hline 15 & $\begin{array}{l}\text { Distressed partners and caregivers do not recover easily:adjustment trajectories } \\
\text { among partners and caregivers of cancer survivors }\end{array}$ & Lambert SD & 7 & 46 \\
\hline 16 & $\begin{array}{l}\text { A rasch analysis of the hospital anxiety and depression scale (HADS) among cancer } \\
\text { survivors }\end{array}$ & Lambert SD & & \\
\hline 17 & $\begin{array}{l}\text { The body image drawing analysis in women with breast disease and breast cancer: } \\
\text { anxiety, colour and depression categories }\end{array}$ & Eskelinen M & 8 & 41 \\
\hline 18 & Evaluation of women with breast disease using body image drawing analysis & Eskelinen M & & \\
\hline 19 & Charting a new course for the delivery of High-quality cancer care & Ganz PA & 9 & 40 \\
\hline 20 & $\begin{array}{l}\text { Supportive care during treatment for breast cancer: resource allocation in low-and } \\
\text { middle-income countries. a breast health global initiative } 2013 \text { consensus statement }\end{array}$ & Cardoso F & & \\
\hline 21 & $\begin{array}{l}\text { eview of psychotherapeutic interventions on depression in cancer patients and their } \\
\text { impact on disease progression }\end{array}$ & Barrera L & 10 & 40 \\
\hline 22 & Minding the body: psychotherapy and cancer survival & Spiegel D & & \\
\hline
\end{tabular}




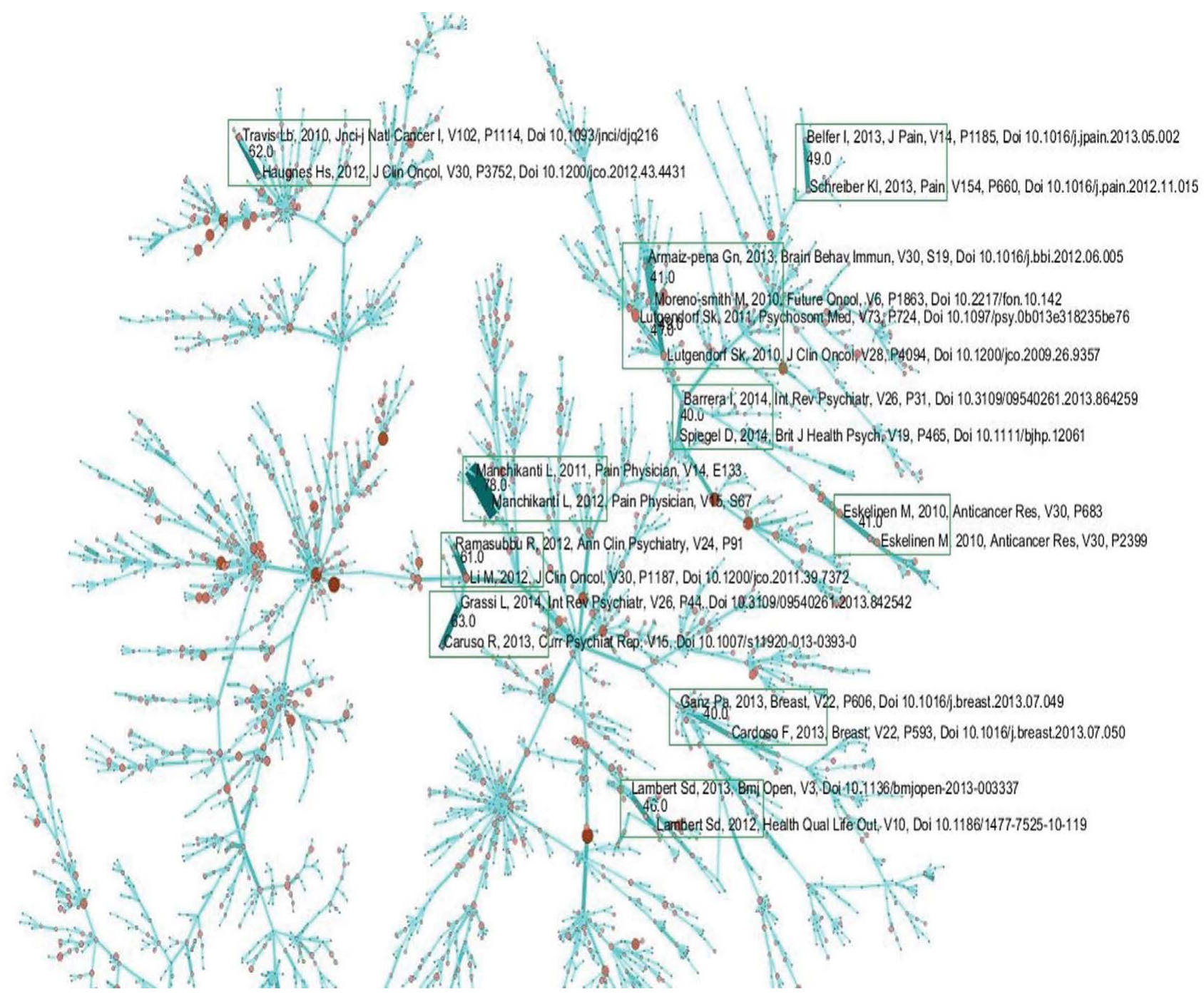

Figure 4: The paper bibliographic coupling map (2010 -2014).

of psychopharmacology and the important of cancer patients' quality of life. The third coupling papers were "Long-term and late effects of germ cell testicular cancer treatment and implications for follow-up" written by Haugnes HS in 2012 [30] and "Testicular cancer survivorship: research strategies and recommendations" written by Travis LB in 2010 [31] and the strength of coupling was 62 . Their primary domain of research was assessment of the overall burden of medical and psychosocial morbidity. The forth coupling papers were "Evidence-based treatment of depression in patients with cancer" written by Li M in 2012 [32] and "The Canadian network for mood and anxiety treatments (CANMAT) task force recommendations for the management of patients with mood disorders and select comorbid medical conditions" written by Ramasubbu R in 2012 [33] and the strength of coupling was 61 . Their primary domain of research was both psychosocial and pharmacologic interventions in treating mental illness in cancer. The fifth coupling papers included three coupled pairs. The first was "Biobehavioral factors and cancer progression: physiological pathways and mechanisms" written by Lutgendort SK in 2011 [34] and "Host factors and cancer progression: biobehavioral signaling pathways and interventions" written by Lutgendort SK in 2010 [35] and the strength of coupling was 45 . The second was "Host factors and cancer progression: biobehavioral signaling pathways and interventions" written by Lutgendort SK in 2010 [35] and "Impact of stress on cancer metastasis" written by Moreno-Smith M in 2010 [36] and the strength of coupling was 49. The third was "Impact of stress on cancer metastasis" written by Moreno- 
Smith M in 2010 [36] and "Src activation by beta-adrenoreceptors is a key switch for tumor metastasis" written by Armaiz-Pena GN in 2013 [37] and the strength of coupling was 47 . Their primary domain of research was physiological and psychological pathways and Mechanisms for therapy of cancer. The sixth coupling papers were "Persistent pain in postmastectomy patients: comparison of psychophysical medical, surgical, and psychosocial characteristics between patients with and without pain" written by Schreiber in 2013 [38] and "Persistent postmastectomy pain breast cancer survivors: analysis of clinical, demographic, and psychosocial factors" written by Belfer L in 2013 [39] and the strength of coupling was 49 . Their primary domain of research was the influence of psychosocial factors for persistent postmastectomy pain in breast cancer. The seventh coupling papers were "Distressed partners and caregivers do not recover easily: adjustment trajectories among partners and caregivers of cancer survivors" written by Lambert SD in 2012 [40] and "A rasch analysis of the hospital anxiety and depression scale (HADS) among cancer survivors" also written by Lambert SD in 2013 [41] and the strength of coupling was 46. Their primary domain of research was the psychiatric rating scale for cancer survivors. The eighth coupling papers were "The body image drawing analysis in women with breast disease and breast cancer: anxiety, colour and depression categories" written by Eskelinen M in 2010 [42] and "Evaluation of women with breast disease using body image drawing analysis" also written by Eskelinen $M$ in 2010 [43] and the strength of coupling was 41 . Their primary domain of research was the association between the effects of psychological factors and development of breast cancer in women. The ninth coupling papers were "Charting a new course for the delivery of High-quality cancer care" written by Ganz PA in 2013 [44] and "Supportive care during treatment for breast cancer: resource allocation in low-and middle-income countries. A breast health global initiative 2013 consensus statement" written by Cardoso F in 2013 [45] and the strength of coupling was 40. Their primary domain of research was the association between psychosocial aspects and high-quality cancer care. The tenth coupling papers were "Review of psychotherapeutic interventions on depression in cancer patients and their impact on disease progression" written by Barrera L in 2014 [46] and "Minding the body: psychotherapy and cancer survival" written by Spiegel D in 2014
[47] and the strength of coupling was 40. Their primary domain of research was the influence of psychotherapeutic interventions on symptoms of mental disease and disease progression and mortality on cancer patients.

\section{Discussion}

The study on the relationship between psychological factors and oncology originated in the 1980's and was gradually developing in the 21th century. We can detect the research direction in the following developmental trend by the analysis on paper bibliographic coupling in this field from 2000 to 2014 .

In the stage of 2000 to 2004, the main research direction was psychological behavior intervention on cancer. In other words, carcinogenic mechanism of psychological factor and the influence of their psychological situation on the prognosis of cancer patients were other two main research directions at this stage.

In the stage of 2005 to 2009 , the influence on the prognosis of tumor patients of their psychological state was still a research direction. In this stage, the cancer with mental illness, the influence of their psychological state on life quality of the cancer patients, the relationship between the psychological state and prognosis of cancer patients and the breast cancer patients' psychological state were other research directions.

In the stage of 2010 to 2014, the influence of their psychological state on life quality of the cancer patients, the breast cancer patients' psychological state was still two research directions. In this stage, the research directions that the function of psychological intervention for chronic pain of the cancer patients, psychological assessment scales for the cancer patients, the combined effect of psychological intervention and pharmaceutical drug for the cancer patients, the influence of psychotherapeutic interventions on symptoms of mental disease and disease progression and mortality on cancer patients were added to be hot research topics.

From the above analysis, the carcinogenic mechanism of psychological factor was always focus direction. At present, we think the carcinogenic mechanism of psychological factor is taken effect by the approach of psychophysiology which is psychological-nerve-endocrine-immune system. when the psychosocial factors effect on the individual who do cognitive assessment, then 
produce negative emotions, the hypothalamus affect the function of endocrine which reduce immune functioning by means of the pituitary and benefit to tumor growth. In recent year, the study on life quality of the cancer patients has been one of international research focus which is widely applied to assessment of cancer and provides the basis for drug screening and clinic treatment. Many studies showed that the psychosocial intervention can improve psychological status and life quality and prolong survival time of cancer patients. In the world, the mortality rate of breast cancer is increasing obviously and is at the first place in female malignant cancers. With the change from traditional biomedical mode to modern "biological-psychological-social" medical mode, the breast cancer patients' psychological state is more and more paid attention to. The breast cancer which seriously effect patients' living quality and marital quality not only threaten the patients' life but also damage female sexual characteristics. So the patients with the breast cancer especially the women have their special psychological characteristics and how to make them promote the mental recovery has been a hot topic which many clinical and psychological doctors are researching on. In other words, the research directions that the function of psychological intervention for chronic pain of the cancer patients, psychological assessment scales for the cancer patients, the combined effect of psychological intervention and pharmaceutical drug for the cancer patients and the influence of psychotherapeutic interventions on symptoms of mental disease and disease progression and mortality on cancer patients were hot research topics in recent years.

\section{Conclusions}

The study on the relationship between psychological factors and oncology has emerged and developed rapidly in recent twenty years. This study built mapping knowledge domain of paper bibliographic coupling by the visualization software, we can reveal the important authors and research directions clearly in different period of time in this field in order to provide a scientific basis for researchers and policy makers in this field and acquire more valuable information and promote rapid development of this area.

Abbreviations
ASIPP: American society of interventional pain
physicians
CANMAT: The Canadian network for mood
and anxiety treatments
Acknowledgements
The authors gratefully acknowledge the support
for this study from "Analysis on Scientific
Collaboration and Trends Prediction of Research
Fronts in Psychiatry Field (No. 71503152)",
awarded by National Natural Science Foundation
of China. This study also supported by Program
for the Outstanding Innovative Teams of Higher
Learning Institutions of Shanxi (OIT).

\section{References}

1. Tang LL, Wang JP: Psycho-oncology. Beijing: Peking University Medical Press (2012).

2. Ma RM, Ni CQ. Author Coupling Analysis: An Exploratory Study on a New Approach to Discover Intellectual Structure of a Discipline. J. Lib. Sci. China 38(198), 4-11 (2012).

3. Vladutz G, Cook J. Bibliographic Coupling and Subject relatedness. American Society for Information Science Proceedings of the 47th ASIS Annual Meeting. Philadelphia: Institute for Science Information 204-207 (1984).

4. Sherman AC, Mosier J, Leszcz M, et al. Group interventions for patients with cancer and HIV disease: Part I : Effects on psychosocial and functional outcomes at different phases of illness. Int. J. Group. Psychoth 54(1), 29-82 (2004).

5. Sherman AC, Mosier J, Leszcz M, et al. Group interventions for patients with cancer and
HIV disease: Part III :morderating variables and mechanisms of action. Int. J. Group. Psychoth 54(3), 347-387 (2004).

6. Holland JC: Improving the human side of cancer care: Psycho-oncology's contribution. Cancer. J 7(6), 458-471 (2001).

7. Holland JC. History of psycho-oncology: Overcoming attitudinal and conceptual barriers. Psychosom. Med 64(2), 206-221 (2002).

8. Holland JC. Psychological care of patients: Psycho-oncology's contribution. J. Clin. Oncol 21(23), 253S-265S (2003)

9. Reynaert C, LibertY, Janne P. Psychogenesis of cancer: between myths, misuses and reality. $B$. Cancer 87(9), 655-664 (2000).

10. Reynaert C, LibertY, Janne P. Psychogenesis of cancer: towards a psycho-neur-endocrinoimmunological way. Ann. Med-Psychol 159(4), 273-284 (2001).
11. Schussler G, Schubert C. The influence of psychosocial factors on immune system (psychoneuroimmunology) and their role for the incidence and progression of cancer. $Z$. Psychosom. Med. Psyc 47(1), 6-41 (2001).

12. Garssen B. Psychological factors and cancer development Evidence after 30 years of research. Clin. Psychol. Rev 24(3), 315-338 (2004).

13. Mustian KM, Morrow GR, Carroll JK, et al. Inegrative nonpharmacologic behavioral interventions for the management of cancerrelated fatigue. Oncologist 12(S), 52-67 (2007).

14. Kangas M, Bovbjerg DH, Montgomery GH. Cancer-related fatigue: A systematic and meta-analytic review of non-pharmacological therapies for cancer patients. Psychological. Bulletin 134(5), 700-741 (2008).

15. Goedendorp MM, Gielissen MFM, Verhagen C, et al. Psychosocial interventions for reducing fatigue during cancer treatment in adults. 
Cochrane. Database. Syst. Rev 1 (2009).

16. Mitchell SA, Berger AM. Cancer-related fatigue: The evidence base for assessment and management. Cancer. J 12(5), 347-387 (2006).

17. Gerharz EW, Mansson A, Mansson W. Quility of life in patients with bladder cancer. Urol. Oncol-Semin. Ori 23(3), 201-207 (2005).

18. Gerharz EW, Mansson A, Hunt S, et al. Quality of life after cystectomy and urinary diversion: An evidence based analysis. $J$. Urol 174(5), 1729-1736 (2005).

19. Magai C, Consedine N, Neugut Al, et al. Common psychosocial factors underlying breast cancer screening and breast cancer treatment adherence: A conceptual review and synthesis. J. Womens. Health 16(1), 1123 (2007).

20. Magai C, Consedine NS, Adjei BA, et al. Psychosocial influences on suboptimal adjuvant breast cancer treatment adherence among African American women implications for education and intervention. Health. Educ. Behav 35(6), 835854 (2008).

21. Lehto US, Ojanen M, dyba T, et al. Baseline psychosocial predictors of survival in localized melanoma. J. Psychosom. Res 63(1), 9-15 (2007).

22. Lehto US, Ojanen M,dyba T, et al. Baseline psychosocial predictors of survival in localized breast cancer. Brit. J. Cancer 94(9), 1245-1252 (2006).

23. Prati G, Pietrantoni L. Optimism, social support, and coping strategies as factors contributing to posttraumatic growth: $A$ meta-analysis. J. Loss. Trauma 14(5), 364388 (2009).

24. Helgeson VS, Reynolds KA, Tomich PL. A meta-analytic review of benefit finding and growth. J. Consult. Clin. Psych 74(5), 797-816 (2006).

25. Manchikanti L, Vallejo R, Manchikanti KN, et al. Effectiveness of long-term opioid therapy for chronic non-cancer pain. Pain. Physician 14(2), E133-E156 (2011).

26. Manchikanti L, Abdi S, Atluri S, et al. American society of interventional pain physicians(ASIPP) guidelines for responsible opioid prescribing in chronic non-cancer pain: part 2-guidance. Pain. Physician 15(3), S67-S116 (2012).

27. Grassi L, Caruso R, Hammelef K, et al. Efficacy and safety of pharmacotherapy in cancer-related psychiatric disorders cross the trajectory of cancer care: A review. Int. Rev. Psychiatry 26(1), 44-62 (2014).

28. Caruso R, Grassi L, Nanni MG, et al. Psychopharmacology in psycho-oncology. Current. Psychiatry. Rep 15(9) (2013).

29. Haugnes HS, Bosl GL, Boer H, et al. Longterm and late effects of germ cell testicular cancer treatment and implications for follow-up. J. Clin. Oncol 30(30), 3752-3763 (2012).

30. Travis LB, Beard C, Allan JM, et al. Testicular cancer survivorship: research strategies and recommendations. JNCl-J. Natl. Cancer. I 102(15), 1114-1130 (2010).

31. Li M, Fitzgeaid P, Rodin G. Evidence-based treatment of depression in patients with cancer. J. Clin. Oncol 30(11), 1187-1196 (2012).

32. Ramasubbu R, Taylor VH, Saaman Z, et al. The Canadian network for mood and anxiety treatments (CANMAT) task force recommendations for the management of patients with mood disorders and select comorbid medical conditions. Ann. Clin. Psychiatry 24(1), 91-109 (2012).

33. Lutgendorf SK, Sood AK. Biobehavioral factors and cancer progression: physiological pathways and mechanisms. Psychosom. Med 73(9), 724-730 (2011).

34. Lutgendorf SK, Sood AK, Antoni MH. Host factors and cancer progression: biobehavioral signaling pathways and interventions. J. Clin. Oncol 28(26), 40944099 (2010).

35. Moreno-Smith M, Lutgendorf SK, Sood AK. Impact of stress on cancer metastasis. Future. Oncol 6(12), 1863-1881 (2010).

36. Armaiz-Pena GN, Allen JK, Cruz A, et al. Src activation by beta-adrenoreceptors is a key switch for tumor metastasis. Nature. Comm 4 (2013).

37. Schreiber KL, Martel MO, Shnol H, et al. Persistent pain in postmastectomy patients: comparison of psychophysical medical, surgical, and psychosocial characteristics between patients with and without pain. Pain 154(5), 660-668 (2013).

38. Belfer L, Schreiber KL, Shaffer JR, et al. Persistent postmastectomy pain breast cancer survivors: analysis of clinical, demographic, and psychosocial factors. J. Pain 14(10), 1185-1195 (2013).

39. Lambert SD, Pallant JF, Boyes AW, et al. Distressed partners and caregivers do not recover easily: adjustment trajectories among partners and caregivers of cancer survivors. Ann. Behav. Med 44(2), 225-235 (2012).

40. Lambert SD, Pallant JF, Boyes AW, et al. A rasch analysis of the hospital anxiety and depression scale (HADS) among cancer survivors. Psychol. Assess 25(2), 379-390 (2013).

41. Eskelinen M, Ollonen P. The body image drawing analysis in women with breast disease and breast cancer: anxiety, colour and depression categories. Anticancer. Res 30(2), 683-691 (2010).

42. Eskelinen M, Ollonen P. Evaluation of women with breast disease using body image drawing analysis. Anticancer. Res 30(6), 2399-2406 (2010).

43. Ganz PA, Levit LA. Charting a new course for the delivery of high-quality cancer care. J. Clin. Oncol 31 (36), 4485 (2013).

44. Cardoso F, Base N, Distellhorst SR, et al. Supportive care during treatment for breast cancer: resource allocation in low-and middle-income countries. A breast health global initiative 2013 consensus statement. Breast 22(5), 593-605 (2013).

45. Barrera L, Spiegel D. Review of psychotherapeutic interventions on depression in cancer patients and their impact on disease progression. Int. rev. Psych 26(1), 31-43 (2014).

46. Spiegel D. Minding the body: psychotherapy and cancer survival. Brit. J. Health. Psych 19(3), 465-485 (2014).

47. Ross L, Boesen EH, Dalton SO. Minding and cancer: dose psychosocial intervention improves survival and psychological wellbeing? Eur. J. Cancer 38(1), 1447-1457 (2002). 